\title{
Demographic Factors, Corporate Social Responsibility, Employee Engagement and Corporate Reputation: A Perspective From Hotel Industries In Indonesia
}

\author{
Juniati Gunawan \\ Trisakti University, Jakarta, Indonesia \\ Zico Dian Paja Putra \\ PT Wijaya Karya, Jakarta, Indonesia
}

\begin{abstract}
Hotel as a hospitality industry should manage its reputation as a valuable asset for the business continuity. The hotel's reputation is built up by the employee's perceptions of treatment and sense of belonging and engagement of the hotel. The purpose of this study is to analyze employee's perceptions of corporate social responsibility (CSR) activities, employee engagement, and corporate reputation that have been undertaken by the hotel industry in Jakarta and how demographic factors influence these perceptions. The structure equation model (SEM) was implemented to find each variable influence. Samples were taken from hotel employees who work in five-star hotels in Jakarta with 221 respondents (response rate 78.9\%). The results indicate that CSR activities significantly influence employee engagement and corporate reputation, and at the same time, employee engagement significantly influences corporate reputation.
\end{abstract}

Keywords: demographic factors, corporate social responsibility (CSR), employee engagement, corporate reputation

\section{Introduction}

Data of Jakarta's culture and tourism division in 2011 have shown that there were 108 hotels of the hospitality industry in Jakarta. So, it is not surprising that the hotel industry has been ranked as the second largest contributor to economic growth in Jakarta under the manufacturing industry (Jakarta Central Bureau of Statistics, 2011).

Hotel has become an important role in the business world as it provides social and economic benefits due to its activities and jobs it creates. Nevertheless, a hotel also has an unfavorable impact on the natural, social, and economic environment as contributing to climate change, air, and water pollution, as well as other socio-economic issues (Grasbois, 2012).

Therefore, the hospitality industry should be able to cope with such problems as a part of its business ethics. One way to reduce the negative impact of the hospitality business activity is to conduct activities related to CSR.

Juniati Gunawan, Ph.D., Trisakti University, Jakarta, Indonesia.

Zico Dian Paja Putra, Master of Management in CSR, PT Wijaya Karya, Jakarta, Indonesia.

Correspondence concerning this article should be addressed to Juniati Gunawan, Kyai Tapa 1, Grogol, West Jakarta, Indonesia. E-mail: yuni_gnw@hotmail.com. 
In the development of the hospitality industry, they are required to conduct their activities in an ethical manner to boost their reputations (Jung, Namkung, \& Yoon, 2010). Research conducted by Jung et al. (2010) revealed that the hotel manager, who works ethically, would make more proactive decisions. As a consequence, the interactions of managers and employees in particular, are generally very influential on the hotel's reputation.

Karani (2011) stated that in addition to enhancing the reputation, CSR activities can also affect patterns of work and a sense of ownership to the employees of the hotel where they work, so they become more productive. Sense of belonging, ownership, and building the company's reputation, is not separated from the perception of the workers themselves. Thus, perception that arises is influenced by demographic factors.

\section{Formulation of Problem}

This study aims to answer the following questions:

(1) How do good demographic factors significantly influence CSR, corporate reputation, and employee engagement, in terms of age, job title/position, division, education, and years of work?

(2) Does CSR significantly influence corporate reputation?

(3) Does CSR significantly influence employee engagement?

(4) Does employee engagement significantly influence corporate reputation?

\section{Literature Review}

\section{CSR Theory}

CSR is the continuing commitment by business to act ethically and contribute to economic development of the local community or society at large, along with an increase in the living standards of workers and their entire family (Kotler \& Lee, 2005).

The international finance corporation has defined CSR as: The commitment of business to contribute to sustainable economic development working with employers and their representatives in the local community and large to improve quality of life, in that are both good for business and good foe development.

\section{Stakeholder Theory}

The concept of CSR has been known since the early 1970s, which is commonly known as the stakeholder theory - that means as a collection of policies and practices relating to the stakeholders, values, compliance with legal requirements, respect for the community and the environment, as well as commitment to the corporate world to contribute to sustainable development (Freeman, 2002).

The survival of the company depends on the support of stakeholders and the support should be sought so that the activity of the company is to seek the support; social disclosure is considered as part of the dialogue between the company and stakeholders (Gray, Kouhy, \& Lavers, 1995). The company is not only an operating entity for its own sake, but for the support of stakeholders; companies must provide benefits to the stakeholders (Gray et al., 1995).

\section{Corporate Reputation Theory}

According to Fombrun (1996), the theory initiates the reputation of corporate identity as the first point that is reflected through the company's name and other views, for example, from annual reports, brochures, 
product packaging, office interiors, employee uniforms, advertising, media, written materials, and audio-visual. He defined corporate reputation as a perceptual representation company's past action and future prospects that describe the firm's overall appeal to all of its key constituents when comparing with other leading rivals. According to him, there are four sides of a reputable company that need to be addressed: credibility (credibility in the eyes of investors), trustworthiness (trustworthy in the eyes of employees), reliability (reliable in the eyes of consumers), and responsibility (responsibility in the eyes of community) (Figure 1).

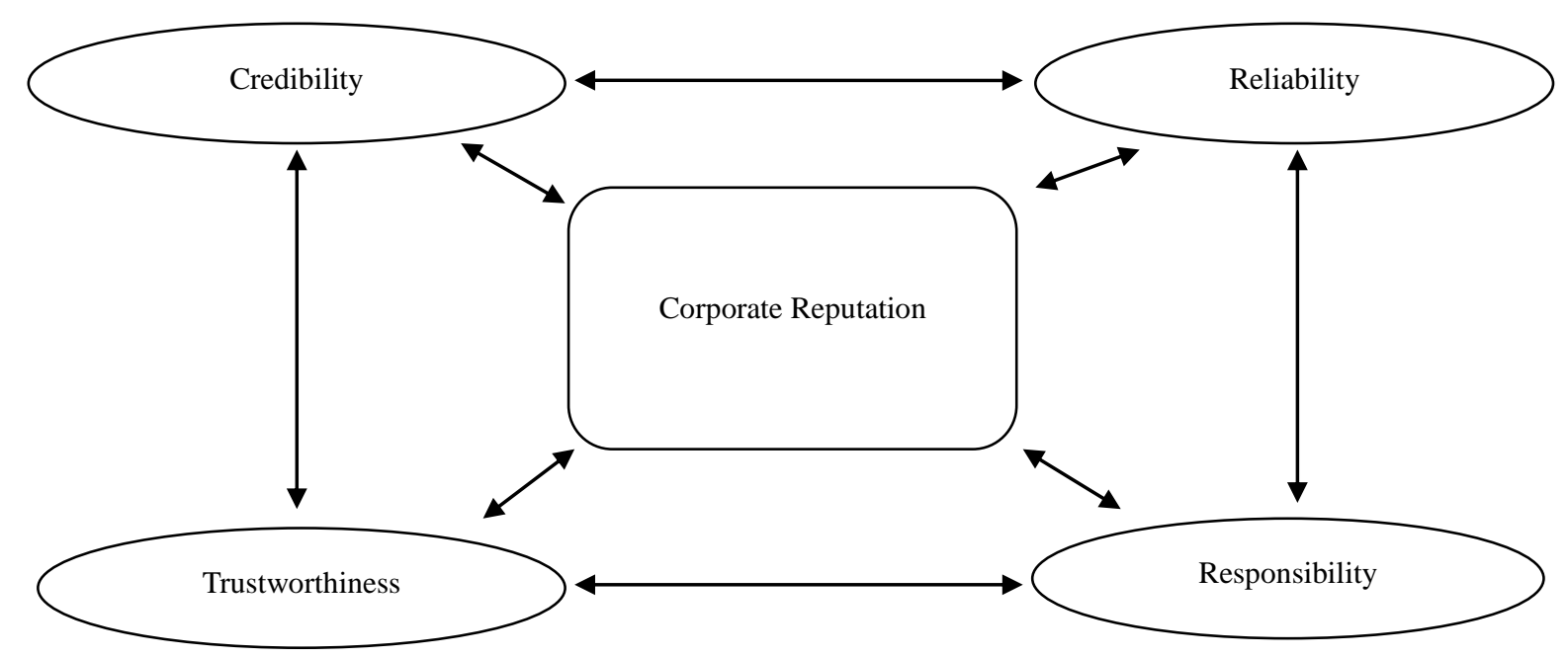

Figure 1. Interaction of corporate reputation. Source: Fombrun (1996).

Reputation differs from image, because it is built for a long period and not just a perception at any given time. Reputation is different from the identity, because reputation is a product of the company's internal constituents. A strong reputation has strategic implications for a company.

\section{Employee Engagement Theory}

Employee engagement has been used extensively and has become a popular term (Saks, 2006). Further, He also stated that there is still a bit of academic and empirical research on the topic which has become so popular. He revealed that employee engagement is the emotional connection and high intellectual owned by the employee towards his job, organization, manager, or co-worker who affects increasing discretionary effort on the job.

Employee engagement in the academic literature has been defined as a unique and distinct construct containing components of cognitive, emotional, and behavior related to individual performance. Furthermore, engagement can be distinguished from several related constructs, such as organizational commitment, organizational citizenship behavior, and job involvement (Saks, 2006).

\section{Perception Theory}

Perception is the process of organizing and interpreting patterns of stimuli in the environment. The study of perception is related to the study of cognitive processes, such as memory and thinking (R. L. Atkinson \& R. C. Atkinson, 1997). Further, perception is like what people see-it is the concept that people have about themselves and others or other (Back, 1977). 


\section{Demographic Factors With CSR, Corporate Reputation, and Employee Engagement}

Age, gender, education, and years of work have significant impacts on organizational commitment (Akintayo \& Abu, 2006). Research conducted by Rehman, Yousaf, and Zia (2010) showed that there is a significant relationship between the organizational commitment and job satisfaction with CSR. Dan (2010) reported that job satisfaction has a positive effect on CSR and employee engagement.

Age. Research conducted by Akintayo (2003) reported that the turnover intention has a negative correlation with age. Ali et al. (2010) revealed that there is a significant correlation between organizational commitment to CSR and the desire of turnover.

Title/Position. Based on the results of the study conducted by Akintayo and Abu (2006), the perception of employees on job satisfaction is influenced by the position/positions. Title/position also affects the feel of the company's employee engagement (Alfermann, 2011).

Division. In the hospitality industry, the food and beverage division has a crucial function in conducting its operations and has very high ethical standards. If they're violated, it will affect the declining occupancy rates and the reputation of being a bad hotel in addition to the direct impact on the health of customers (Jung et al., 2010).

Education. The level of education has a significant impact on organizational commitment (Akintayo \& Abu, 2006). Akintayo and Abu (2006) stated that graduated workers have a higher commitment to the organization than the non-graduated ones.

Years of Work. Research conducted by Akintayo (2003) reported that the turnover has a negative correlation with organizational commitment. Potential causes of this situation are age, length of work, career satisfaction, and desire to turnover.

\section{CSR and Corporate Reputation}

Hoffman (2011) assumed that the company requires recognition and social acceptance for the long-term viability (business) with emphasis on the emotional aspects of reputation building. A simple scheme tends to intensify the perception of higher emotional reactions. On the other hand, according to Hoffman, secondary positive affective reaction is a response to events which may be unexpected.

\section{CSR and Employee Engagement}

Ma (2011) concluded, if companies execute CSR initiatives based on the values of the company, the company has the power to improve the employee recruitment, satisfaction, and retention. The Massachusetts business roundtable (MBR) supports this idea by saying that the values of CSR activity of the company can become a part of the employee value proposition.

\section{Employee Engagement and Corporate Reputation}

The role of employees is essential in the creation and maintenance of the company's reputation (Cravens \& Oliver, 2006). Cravens and Oliver (2006) through the model, indicated that the identity of the company is a starting point in the creation of two things: the company's image and reputation of the company. Corporate identity consists of goals, values, strategy, and organizational culture (Cravens \& Oliver, 2006). Through communications to both internal and external stakeholders, the company can create a reputation.

\section{Framework of Thinking}

Perspective of hotel industries in Indonesia as a basis to this study is presented in Figure 2. 


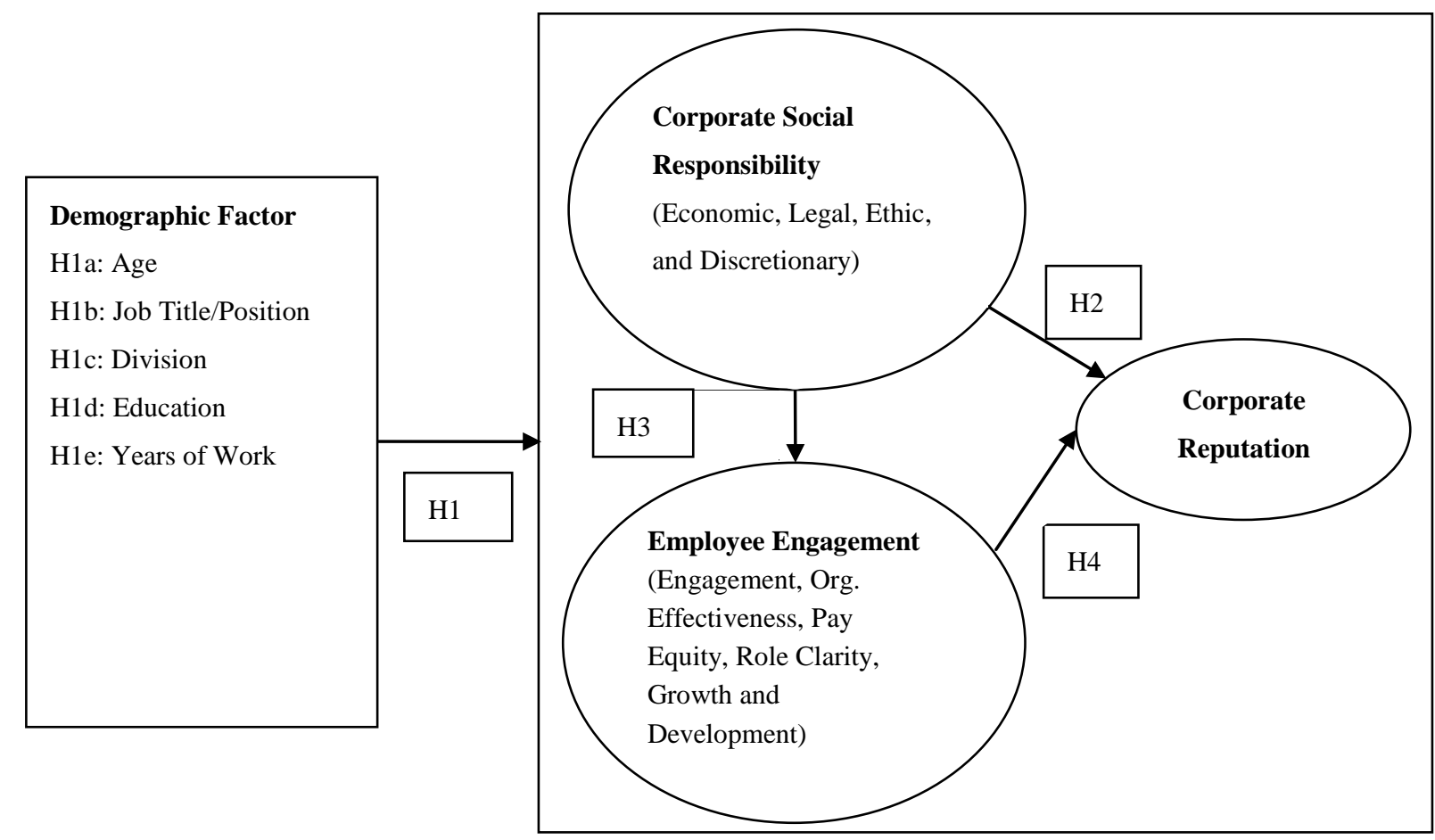

Figure 2. Relationship between demographic factors, CSR, corporate reputation and employee engagement framework.

\section{Research Hypothesis and Methodology}

\section{Research Hypothesis}

H1: Demographic factors significantly influence CSR, corporate reputation, and employee engagement.

- H1a: Age significantly influences CSR, corporate reputation, and employee engagement;

- H1b: Job title/position significantly influences CSR, corporate reputation, and employee engagement;

- H1c: Division significantly influences CSR, corporate reputation, and employee engagement;

- H1d: Education significantly influences CSR, corporate reputation, and employee engagement;

- H1e: Years of work significantly influences CSR, corporate reputation, and employee engagement.

H2: CSR significantly influences corporate reputation.

H3: CSR significantly influences employee engagement.

H4: Employee engagement significantly influences corporate reputation.

\section{Research Methodology}

This research uses exploratory quantitative method, using surveys and hypotheses test. The development of questionnaire refers to the various studies that have been conducted previously. The CSR variables of Maignan and Ferrell (2001) were adopted with the item statements consisting of four dimensions of CSR (economic, legal, ethics, and philanthropy). Corporate reputation questionnaire was adopted from Helm (2007), and the questions for employee engagement were adopted from Alfermann (2011).

This study uses primary data by purposive random sampling and the samples are five-star hotels which are located in Jakarta. In total, there are 26 five-star hotels in Jakarta. By using the Slovin formula (E-value of $20 \%$ ), at least 13 hotels should be used as samples. 
With a population of 12,676 people, the number of samples can be determined by using the Slovin formula, as follows:

$$
\frac{N \text { total }}{N(e)^{2}+1} n=\frac{12,676}{12,676 \times(0.1)^{2}+1} \approx 99.2 \approx 100
$$

Where, $e=10 \%=0.1 ; N$ total $=12,676 ; n=100$.

Based on the number of respondents who have been determined with the non-probability random sampling techniques, the sampling techniques allotment (quoted sampling) had been used and each hotel had been given up to 20 questionnaires and a total of 280 questionnairs were given out. A total of 221 out of 280 questionnaires were returned and were able to be used in this study, so that response rate of the study was $78.9 \%$.

The ANOVA procedure of data processing is performed to test differences in the mean values between two or more groups. The value of average difference being tested can be caused by the independent variable.

The data analysis method used in this research is the SEM using LISREL software version 8:54.

\section{Result and Discussion}

\section{ANOVA Test Result}

ANOVA test results for each of the demographic variables are as follows (Table 1).

Table 1

ANOVA Test Results for Demographic Factor

\begin{tabular}{llll}
\hline Demographic factor & Variable & $p$-value standard & $p$-value result \\
\hline \multirow{3}{*}{ Age } & CSR & & 0.852 \\
& CR & $<0.05$ & 0.103 \\
& EE & & 0.029 \\
Job title/Position & CSR & & 0.019 \\
& CR & $<0.05$ & 0.003 \\
Eivision & EE & & 0.27 \\
& CSR & & 0.201 \\
& CR & $<0.05$ & 0.03 \\
Education & EE & & 0.075 \\
& CSR & & 0.012 \\
Years of work & CR & $<0.05$ & 0.492 \\
& EE & & 0.09 \\
& CSR & & 0.537 \\
\hline
\end{tabular}

Notes. CR: corporate reputation; EE: employee engagement.

\section{SEM}

Based on the output of the SEM analysis (LISREL series 8:54), here are the overall values obtained by testing the model in Table 2. 
Table 2

Goodness of Fit Models

\begin{tabular}{lllll}
\hline Kinds of measurement & Measurement & Result & Standard value & Conclusions \\
\hline & Chi-square & 148.62 & $p$-value $>0.05$ close to 0.1 & Goodness of fit \\
& $p$-value & 0.14 & $>0.9$ close to 1 & Goodness of fit \\
Absolute fit measures & GFI & 0.93 & $<0.05$ & Goodness of fit \\
& RMR & 0.020 & $<0.08$ close to 0.1 & Goodness of fit \\
& RMSEA & 0.025 & $>0.9$ close to 1 & Goodness of fit \\
& AGFI & 0.9 & $>0.9$ close to 1 & Goodness of fit \\
Incremental fit measures & NNFI/TLI & 1.00 & $>0.9$ close to 1 & Goodness of fit \\
& CFI & 0.98 & $>0.9$ close to 1 & Goodness of fit \\
& RFI & 1.00 & $>0.9$ close to 1 & Goodness of fit \\
Parsimonious fit & IFI & 0.97 & $>0.9$ close to 1 & Goodness of fit \\
Neasures & Normed Chi-square & 3.866 & Lower level: 3 & Goodness of fit \\
\hline
\end{tabular}

Notes. CR: corporate reputation; EE: employee engagement. Source: LISREL result.

\section{Hypothesis Testing}

After using the ANOVA for demographic factors, the results of $p$-value for each demographic factor can be seen in the Table 3 .

Table 3

Hypothesis 2 Test Results

\begin{tabular}{|c|c|c|c|c|}
\hline Demographic Factor & Variable & $p$-value standard & $p$-value result & Conclusions \\
\hline \multirow{3}{*}{ Age } & CSR & \multirow{3}{*}{$<0.05$} & 0.852 & Not significant \\
\hline & $\mathrm{CR}$ & & 0.103 & Not significant \\
\hline & $\mathrm{EE}$ & & 0.029 & Significant \\
\hline \multirow{3}{*}{ Job title/Position } & CSR & \multirow{3}{*}{$<0.05$} & 0.019 & Significant \\
\hline & $\mathrm{CR}$ & & 0.003 & Significant \\
\hline & $\mathrm{EE}$ & & 0.27 & Not significant \\
\hline \multirow{3}{*}{ Division } & CSR & \multirow{3}{*}{$<0.05$} & 0.201 & Not significant \\
\hline & $\mathrm{CR}$ & & 0.03 & Significant \\
\hline & $\mathrm{EE}$ & & 0.075 & Not significant \\
\hline \multirow{3}{*}{ Education } & CSR & \multirow{3}{*}{$<0.05$} & 0.012 & Significant \\
\hline & $\mathrm{CR}$ & & 0.492 & Not significant \\
\hline & $\mathrm{EE}$ & & 0.09 & Not significant \\
\hline \multirow{3}{*}{ Years of work } & CSR & \multirow{3}{*}{$<0.05$} & 0.537 & Not significant \\
\hline & $\mathrm{CR}$ & & 0.49 & Not significant \\
\hline & $\mathrm{EE}$ & & 0.01 & Significant \\
\hline
\end{tabular}

Notes. CR: corporate reputation; EE: employee engagement.

According the results, thus, it can be stated that: In Hypothesis 1,

- H1a: Age only significantly influences employee engagement;

- H1b: Title/position significantly influences CSR and corporate reputation; 
- H1c: Division significantly influences corporate reputation;

- H1d: Education significant influences CSR;

- H1e: Years of work significantly influences employee engagement.

While to test Hypothesis 2, Table 4 can be seen.

Table 4

Hypothesis 2 Test Results

\begin{tabular}{llllll}
\hline Independent & Dependent & $t$-hitung & $t$-tabel & Loading & Con \\
\hline CSR & CR & 4.40 & 1.96 & 0.59 & Significant \\
\hline
\end{tabular}

Note. CR: corporate reputation.

Thus, H2 - CSR significantly influences corporate reputation, can be confirmed.

Table 5

Hypothesis 3 Test Results

\begin{tabular}{llllll}
\hline Independent & Dependent & $t$-hitung & $t$-tabel & Loading & Con \\
\hline CSR & EE & 6.40 & 1.96 & 0.43 & Significant \\
\hline
\end{tabular}

Note. EE: employee engagement.

In Table 5, H3 - CSR significantly influences employee engagement, can be confirmed.

Table 6

Hypothesis 4 Test Results

\begin{tabular}{llllll}
\hline Independent & Dependent & $t$-hitung & $t$-tabel & Loading & Con \\
\hline EE & $\mathrm{CR}$ & 4.14 & 1.96 & 0.46 & Significant \\
\hline
\end{tabular}

Note. CR: corporate reputation.

In Table 6, H4 -employee engagement significantly influences corporate reputation, can be confirmed.

\section{Other Analysis and Discussion}

Demographic factors with CSR, corporate reputation and employee engagement (H1). Age (H1a).

The demographic results indicate that employees who are tied to their job are over 40 years old. It is associated with cognitive and emotional components of own employees perception who have been working in the hospitality industry for a long time. Some respondents said that for those who are older than 40 years no longer desire to get out of the hotel in which they work and they just want to stay put until retirement.

Different results are shown for those between the ages of 18-28. The younger ones are less committed due to the long working period at the hotel. So they don't sense the cognitive and emotional commitment to the hotel. Less committed can also come from job enrichment and task accuracy (role fit) that have a positive predictor for meaningfulness that is not perceived by young who have less experience.

Job title/Position (H1b). The results of research of Jung et al. (2010) say that the ethical manager will make more proactive decisions and enhance the reputation of the hotel. This corresponds to a position of a manager as the mediator between the company with the employees and the community. Thus, it can be explicitly seen that the manager has an important role in the implementation of the hotel's CSR. The manager is the one who knows and understands the needs of the day-to-day operations, especially for employees. 
For the concept of CSR, it is inevitable that the senior manager must be able to define the long-term strategies, while the managers are the executors of the concept. As for the reputation, to compete in hospitality industry, a senior manager should be maintained the reputation of the hotel.

Division (H1c). The results of research conducted by Karani (2011) showed that CSR influences the desire of employees to work in a hotel which has a good reputation. A good reputation comes from good employees who have gone through a good recruitment system.

Each division has a function with different goals in the hotel. The results showed that the divisions which have a significant effect on the reputation of the company are human resources and general affairs. It is based on the function of HR itself as part of the employee recruitment process. So usually the appearances of recruiters (HR) will be the initial reflection of the impression which is owned by the hotel itself. If a good HR personnel appears to be neat, polite, friendly, and qualified, the same will also be reflected on the employees of the hotel.

Education (H1d). The level of education has a significant impact on organizational commitment (Akintayo \& Abu, 2006). The results of these studies indicate that workers who have a bachelor's degree have higher commitment to the organization compared to their peers who don't have it. For the category of education, it is almost the same as the category of office/position; a manager has usually a minimum education level equivalent to a bachelor's degree. This is because the manager is not only required to just run the operations of the hotel, but it's also required to teach ethics for its employees.

Business ethics stresses that managers and corporations are responsible for implementing ethical principles in their organization and they use moral bases in making decisions, policies and strategies, and dealing with other general issues of the company. In the context of CSR, managers act as moral actors and are responsible for the conduct of responsibility (discretion) on their existing management in all aspects of social responsibility to produce results that are socially responsible.

Years of work (H1e). Similar to the demographic factors of age, it has been noticed that employee engagement is affected by how long the employee worked at the hotel. Long work affects employee's perceptions of the hotel where they work. How they treat their employees can determine the employees' sustainability commitment to the hotel where they work.

Akintayo (2003) reported that the desire of the employee's turnover has a negative correlation with organizational commitment. So it can be said that the larger the organization's commitment to the welfare of employees, the lower the desire to turnover becomes. The potential causes are age, length of work, and career satisfaction.

CSR with corporate reputation (H2). For hotels, reputation is very important and crucial for their survival in the competitive business world. The results of the study conducted by Inoue and Lee (2012) showed that CSR can help build and strengthen the company's reputation when consumers perceive the company as an ethical company. Maintaining a good reputation is very important for any hotel, because bad reputation is likely to have an impact on undesirable matters such as the decline of occupancy rates or the lack of customer wanting to come back to the hotels (Inoue \& Lee, 2012).

Besides consumers, the good reputation of the company can also affect the perception of workers. A key feature in this connection is how organizational culture affects employees' perceptions of corporate image. Once the identity and image of the company are formed, the second thing is to deal with matters that can affect a company's reputation. 
Employees are important stakeholders for the company. Therefore, whether or not the company's reputation depends on the employees' perception of the organization/company as mentioned, CSR can be considered as a medium for the cause or can form the corporate culture.

CSR with employee engagement (H3). Employee engagement with the company is one of the factors that can increase employee's loyalty and productivity. In improving employee engagement, CSR could be one of the tools to achieve this goal. CSR activity based on the company's values aimed to improve employee commitment.

CSR initiatives can be derived from the value of the company's vision, mission, and culture, as well as all employees who are a part of it. Therefore, CSR can have an impact on employee engagement (employee engagement) to a certain extent and instill pride in the company's employees. Increased CSR initiatives progressively raise the amount of investment from the company in the form of business and money, and they also pay attention to current employees of the company's reputation with regard to CSR activities in the corporate workplace.

If hotels conduct CSR initiatives based on the values of the company, the company has the power to improve the employee recruitment, satisfaction, and retention. The results of the study showed that the company's CSR programs are connceted with values of the company itself, and they further relate to employees. The benefits of this relationship are to help the company achieving its goals.

Employee engagement with corporate reputation (H4). The role of employees is essential in the creation and maintenance of a company's reputation. Corporate identity is a starting point of corporate image and reputation. Corporate identity consists of goal, value, strategy, and organizational culture. The employee, which is the core of the company, is a "tool" in terms of creating a company's reputation. They must support the values, goals, and strategies of companies that are creating a culture to maintain a positive corporate reputation.

The good reputation of the company can increase its profits over time. The company's reputation can have an impact on financial performance, so it must be actively managed within the organization. Employees are the first ones meeting the customers, suppliers, and other key partners in person, and their actions may affect the company whether they are positive or negative.

An important part of the process of maintaining the company's reputation is the training and education of employees. Managers at various levels in the organization have an important role in communicating with employees to inform the importance of enhancing the company's reputation. Managers monitor, direct, and evaluate the workers who are empowered to build a reputation and who are beneficial for the organization.

An important component in the control system of management of any organization is a system of incentives used to encourage managers and employees to achieve company goals. Without a good incentive system, employees may not have the motivation or knowledge required to contribute to this goal. This, in turn, leads to the achievement of company performance and can generate sustainable competitive advantage for the company.

\section{Conclusions}

Based on the ANOVA test, the results show that the demographic factors that have a significant relationship with CSR are job title/position and education. The issues having significant relationships with 
corporate reputation are job title/position related to the division. Meanwhile, the issues that have a significant relationship with employee engagement are age and years of work.

Based on SEM, the results show that CSR has a significant relationship with the corporate reputation and employee engagement. Meanwhile employee engagement has a significant relationship with corporate reputation.

Limitation of this study was that it had been conducted only 13 five-star hotels in Jakarta with the data collection period of one month (June 1 to 30, 2012) so that the results of the study can't be generalized. The study had also only been based on employee perceptions, which could be different from other's perception.

Some suggestions for the next study are the need to perform an initial screening associated with employees' perceptions and understanding of CSR by conducting pre-test or applying the method of focus group discussion. In-depth study can be conducted by specifying particular respondents, such as manager or director.

However, further research may also include variables, such as job satisfaction, organizational level of commitment, or may expand the respondents, for example, consumers, suppliers, and shareholders.

\section{References}

Akintayo, D. I. (2003). The influencing leadership orientation and managerial effectiveness on organizational commitment among the church members (unpublished professional paper, University of Ibadan).

Akintayo, D. I., \& Abu, P. B. (2006). The impact of demographic factors on organizational commitment of industrial workers in Lagos State, Nigeria (unpublished professional paper, Olabisi Onabanjo University, Lagos).

Alfermann, A. L. (2011). The effects of corporate social responsibility on employee engagement in a global setting (Unpublished dissertation, Benedictine University, Illinois).

Atkinson, R. L., \& Atkinson, R. C. (1997). Introduction to psychology (8th ed.). Lincoln: Harcourt Brace College Publishers.

Back, K. W. (1977). Social psychology. Hoboken: John Willey \& Sons, Inc..

Cravens, D. W., \& Oliver, D. (2004). The effect of moderators on the salesperson behaviour performance and salesperson outcome performance and sales organization effectiveness relationships. European Journal of Marketing, 36(11/12), $1367-1388$.

Dan, Z. (2010). The impact of employees' perceptions of corporate social responsibility on job attitudes and behaviors : A study in China (Unpublished theses, Singapore Management University, Singapore ).

Fombrun, C. J. (1996). Reputation: Realizing value from the corporate image. Boston: Harvard Business School Press.

Freeman, E. (2002). Strategic management: A stakeholder approach (3rd ed.). Boston: Pitman Publishing.

Grasbois, D. (2012). Corporate social responsibility reporting by the global hotel industry: Commitment, initiatives and performance. International Journal of Hospitality Management, 31, 896-905.

Gray, R., Kouhy, R., \& Lavers, S. (1995). Corporate social and environmental reporting: A review of the literature and a longitudinal study of UK disclosure. Accounting, Auditing \& Accountability Journal, 8(2), 47-77.

Helm, S. (2007). The role of corporate reputation in determining investor satisfaction and loyalty. Corporate Reputation Review, $10(1), 22-37$.

Hoffman, A. J. (2011). Beyond corporate reputation: Managing reputational interdependence. Corporate Reputation Review, $11(1), 45-56$.

Inoue, Y., \& Lee, S. (2011). Effects of different dimensions of corporate social responsibility on corporate financial performance in tourism-related industries. International Journal of Hospitality Management, 31, 790-804.

Jakarta Central Bureau of Statistics. (2011). Jakarta tourism agency (Press Release by BPS DKI Jakarta. No. 49/12/31/Th. XIII.1 December 2011).

Jung, S. H., Namkung, Y., \& Yoon, H. H. (2010). The effects of employees' business ethical value on person-organization fit and turnover intent in the foodservice industry. International Journal of Hospitality Management, 29, 538-546.

Karani, A. P. (2011). Corporate social responsibility and employee recruiting in hospitality and tourism industry (unpublished theses, Purdue University, Indiana). 
Kotler, P., \& Lee, N. (2005). Corporate social responsibility. Hoboken: John Wiley \& Sons, Inc..

Ma, H. (2011). The effects of corporate social responsibility on employee engagement (unpublished theses, University of Southern California)

Maignan, I., \& Ferrell, O. C. (2001). Measuring corporate citizenship in two countries: The case of the United States and France. Journal of Business Ethics, 23, 283-297.

Rehman, K. U., Yousaf, J., \& Zia, M. (2010). Corporate social responsibility influences on employee retention and organizational performance. African Journal of Business Management, 4(13), 2796-2801.

Saks, A. M. (2006). Antecedents and consequences of employee engagement. Journal of Managerial Psychology, 21(7), 660-619. 